\title{
A Systematic Review of the Value of a Bladder Scan in Cauda Equina Syndrome Diagnosis
}

\author{
Awf A. Alshahwani ${ }^{1}$, Joseph Boktor ${ }^{2}$, Amr Elbahi ${ }^{3}$, Purnajyoti Banerjee ${ }^{3}$ \\ 1. Trauma and Orthopaedics, Leicester University Hospital, Leicester, GBR 2. Trauma and Orthopaedics, Cardiff \\ University Hospital, Cardiff, GBR 3. Trauma and Orthopaedics, Kettering General Hospital, Kettering, GBR
}

Corresponding author: Awf A. Alshahwani,dr_awf1985@yahoo.com

\begin{abstract}
Cauda equina syndrome (CES) is one of the emergency conditions that can lead to devastating permanent functional disabilities, if misdiagnosed. Multiple studies have questioned the reliability of clinical assessment in diagnosing CES, whether some of the features should be considered to be potential red flags. Bladder dysfunction can reflect CE compromise. The post-void residual (PVR) volume bladder scan is useful in CES diagnosis, but to date there has been no single systematic review supporting its use. Furthermore, there is no clear cut-off point to consider PVR statistically significant. The aim of the study is to perform a systematic review of the current evidence behind the use of the PVR bladder scan as a diagnostic tool for CES diagnosis. This was a comprehensive search using Medline, PubMed and Embase. All articles included post-void bladder scans with the mentioned clear cut-off volume as a diagnostic parameter. A total of five study articles from 1955 fit with our inclusion and exclusion criteria. The total number of patients who had a bladder scan was 531. CES was confirmed in 85 cases. Bladder scan diagnosed 70 cases and excluded 327. The best results for both sensitivity and specificity in correlation with the sample of the study were for PVR more than $200 \mathrm{ml}$. Measuring the post-void urine volume using a bladder scan is an essential tool in the diagnosis of CES. There is a significant correlation between the PVR volume more than $200 \mathrm{ml}$ and higher sensitivity and specificity.
\end{abstract}

Categories: Orthopedics

Keywords: cauda equina, bladder scan, pvr, screen, adjunct

\section{Introduction And Background}

Cauda equina syndrome (CES) is an emergency spinal pathology that can lead to devastating permanent functional disabilities. It is rare with an estimated incidence of 1 in 2000 [1]. Missing timely diagnosis of cauda equina compression can end up in irreversible bowel, bladder and sexual dysfunction. Missed CES represents the most common diagnoses associated with successful litigation and paying off huge sum of compensation to the victim thereby causing substantial financial strain in every health system in the world. In the United States, nearly half of the claims have been paid, and settlement costs millions of dollars per person $[2,3]$.

Review began 03/31/2021 Review ended 04/05/2021 Published 04/12/2021

\section{(๑) Copyright 2021}

Alshahwani et al. This is an open access article distributed under the terms of the Creative Commons Attribution License CC-BY 4.0., which permits unrestricted use, distribution, and reproduction in any medium, provided the original author and source are credited.
There is a debate in the literature questioning the accuracy of clinical features in the diagnosis of CES including saddle area anesthesia, perineal loss of sensation, sphincter dysfunction, bilateral sciatica, and motor and sensory function disturbances [4]. Magnetic resonance imaging (MRI) scan is essential to rule out cauda equina as no single or collective features will definitely confirm or exclude diagnosis [5]. The British Association of Spine Surgeons (BASS) emphasized that an urgent MRI scan should be performed for suspected CES, and decompressive surgery should be undertaken at the earliest opportunity in confirmed cases [6]. Early surgery is indicated to avoid the permanent functional disability and financial implications associated with a missed diagnosis or inadequate management. Therefore, early diagnosis with an MRI scan is an essential tool to achieve this [7].

As MRI scanning may not be available in peripheral hospitals with no specialist spinal surgical services, an alternative measure is to identify the patient who needs a transfer to the specialist spinal "hub" hospital where MRI scans can be undertaken especially after working hours. These hospitals usually have aroundthe-clock cover for spinal emergencies and might reduce the risk of further delay by undertaking an MRI scan and then surgery if necessary without the need for further consultations or transfer to another center [6]. Furthermore, exposing a patient to an unnecessary imaging study during a situation like coronavirus disease 2019 (COVID-19) pandemic and using the same machine for COVID-positive patient can result, theoretically at least, to an increased spread of the disease, in addition to the burden on the resources [8]. As bladder function can be assessed on a frequent basis through urination, post-void bladder volume represents a surrogate marker of the cauda equina function and the bladder musculature contractions as well [9]. Bladder emptying, which can be accurately assessed by a bladder scan, would be a good criterion [10].

In this study, we have undertaken a systematic review, assessing the efficacy of a bladder scan used as a 
bedside clinical tool in possible diagnosis of cauda equina compression. Furthermore, we have delineated an accurate cut-off point to highlight the possibility of CES and prioritize the patient for a subsequent MRI scan.

Our research question is, "Is bladder scan a suitable tool for screening cauda equina syndrome complementary to clinical examination?" and "What would be the expected significant post-void residual (PVR) volume to proceed to the MRI scan?"

\section{Review}

This systematic review was performed according to the Preferred Reporting Items for Systematic Reviews and Meta-analyses (PRISMA) guidelines as shown in Figure 1.
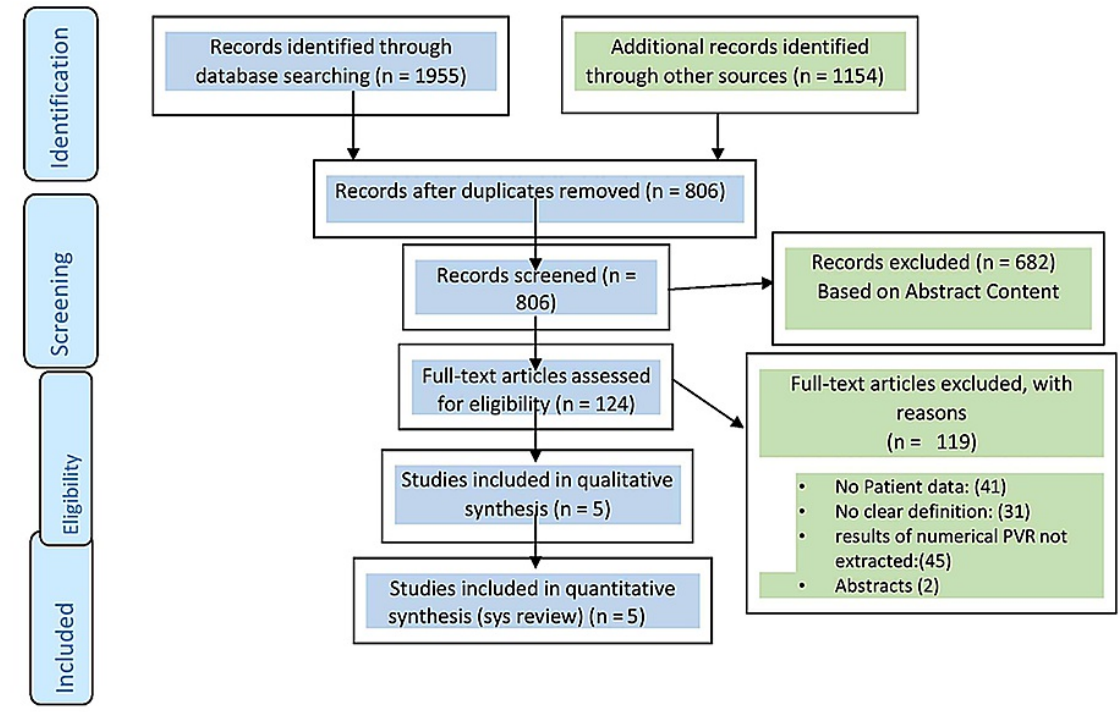

\section{FIGURE 1: PRISMA Flow Diagram}

PRISMA, Preferred Reporting Items for Systematic Reviews and Meta-analyses; PVR, post-void residual

Starting on December 2019, till September 2020, a comprehensive search was done by two spinal surgeons with the help of an experienced librarian. We looked at the databases including Embase, PubMed and Medline. We included original peer-reviewed studies that included numeric values of PVR apparent in bladder scans as a diagnostic tool and MRI scans done to confirm the diagnosis of CES. We excluded (1) abstracts, case reports and studies mentioning high post-void residual volumes but no actual numeric values reported and (2) studies that did not detail urine retention and volume but only mentioned bladder dysfunction. Filtration of studies was done by reading the article title, abstract and for some studies, by reading the full articles. The process was repeated by two authors and unrelated studies were removed after revising.

The first electronic search detected a total of 1955 studies published from 2008 till July 2020. No studies were found before 2008. Removal of duplicates was done and 806 studies remained and were further screened for eligibility based on title and abstract; 120 articles were found eligible. After reading full text, only seven studies met the inclusion criteria. Yet two of the seven were abstracts and were not fully published articles. There was another randomized controlled trial that was stopped due to ethical approval withdrawal [11].

A total of five studies were included in this review. Table 1 shows the key features of these studies. Four of the five studies were retrospective and one study was prospective. In the reviewed papers, the total number of patients who had a bladder scan was 531. CES was confirmed in 85 cases. Bladder scan diagnosed 70 cases 
and excluded 327. We looked at the sensitivity and specificity of each study and found the best results for both sensitivity and specificity in correlation with the sample of the study would be at PVR $>200 \mathrm{ml}$ as shown in Table 2.

\begin{tabular}{|c|c|c|c|c|c|}
\hline Title & $\begin{array}{l}\text { Author \& } \\
\text { Year }\end{array}$ & Study Type & $\begin{array}{l}\text { Total } \\
\text { No. of } \\
\text { Cases }\end{array}$ & $\begin{array}{l}\text { Cases } \\
\text { With } \\
\text { Positive } \\
\text { MRI for } \\
\text { CES }\end{array}$ & Outcome \\
\hline $\begin{array}{l}\text { Predictive value of clinical characteristics in } \\
\text { patients with suspected cauda equina } \\
\text { syndrome [12] }\end{array}$ & $\begin{array}{l}\text { Domen et } \\
\text { al. (2009) }\end{array}$ & Retrospective & 58 & 8 & $\begin{array}{l}\text { A PVR volume more than } 500 \mathrm{ml} \text { with } \\
\text { or without other clinical features of } \\
\text { CES is an important predictor for } \\
\text { CES }\end{array}$ \\
\hline $\begin{array}{l}\text { Does rectal examination have any value in } \\
\text { the clinical diagnosis of cauda equina } \\
\text { syndrome? [5] }\end{array}$ & $\begin{array}{l}\text { Goodıng et } \\
\text { al. (2013) }\end{array}$ & Retrospective & 57 & 13 & $\begin{array}{l}\text { No single clinical feature is adequate } \\
\text { as standalone to discriminate with } \\
\text { statistical significance to proceed to } \\
\text { the MRI outcome }\end{array}$ \\
\hline $\begin{array}{l}\text { The clinical features and outcome of scan- } \\
\text { negative and scan-positive cases in } \\
\text { suspected cauda equina syndrome: a } \\
\text { retrospective study of } 276 \text { patients [13] }\end{array}$ & $\begin{array}{l}\text { Hoeritzauer } \\
\text { et al. (2018) }\end{array}$ & Retrospective & $\begin{array}{l}276 \\
\text { but } \\
\text { only } \\
65 \\
\text { had a } \\
\text { scan }\end{array}$ & 15 & $\begin{array}{l}\text { No PVR records for two-thirds of the } \\
\text { patients }\end{array}$ \\
\hline $\begin{array}{l}\text { Bladder scans and postvoid residual volume } \\
\text { measurement improve diagnostic accuracy } \\
\text { of cauda equina syndrome [9] }\end{array}$ & $\begin{array}{l}\text { Venkatesan } \\
\text { et al. (2019) }\end{array}$ & Prospective & 92 & 17 & $\begin{array}{l}\text { The presence of red flags with a PVR } \\
\text { volume more than } 200 \mathrm{ml} \text { obligates } \\
\text { the necessity of an MRI scan }\end{array}$ \\
\hline $\begin{array}{l}\text { A prospective study of the role of bladder } \\
\text { scanning and post-void residual volume } \\
\text { measurement in improving diagnostic } \\
\text { accuracy of cauda equina syndrome [14] }\end{array}$ & $\begin{array}{l}\text { Katzouraki } \\
\text { et al. (2020) }\end{array}$ & Prospective & 260 & 32 & $\begin{array}{l}\text { Use of the PVR volume } \geq 200 \mathrm{ml} \text { was } \\
\text { considerably more accurate in } \\
\text { predicting CES. It is a useful adjunct } \\
\text { to conventional clinical assessment } \\
\text { and allows risk stratification in } \\
\text { managing suspected CES }\end{array}$ \\
\hline
\end{tabular}

\section{TABLE 1: Key features of the five studies}

PVR, post-void residual; CES, cauda equina syndrome

\begin{tabular}{|l|l|l|l|l|l|l|l|l|}
\hline PVR & Patients & TP & FN & FP & TN & Sensitivity & Specificity \\
\hline Hoeritzauer et al. [13] & $>100$ & 65 & 10 & 5 & 24 & 26 & $67 \%$ & $52 \%$ \\
Venkatesan et al. [9] & $>200$ & 92 & 16 & 1 & 19 & 56 & $94 \%$ & $72 \%$ \\
Domen et al. [12] & $>500$ & 58 & 6 & 2 & 0 & 50 & $100 \%$ & $93 \%$ \\
Gooding et al. [5] & $>500$ & 57 & 6 & 7 & 0 & 44 & $46.1 \%$ & $100 \%$ \\
Katzouraki et al. [14] & $>200$ & 260 & 32 & 2 & 75 & 151 & $94.1 \%$ & $66.8 \%$ \\
\hline
\end{tabular}

TABLE 2: Data analysis from the studies, with sensitivity and specificity

PVR, post-void residual; TP, true positive; FN, false negative; FP, false positive; TN, true negative

CES was first described in the mid-50s by Jennett after correlating symptoms of back pain, sphincter dysfunction with an intraoperatively confirmed disc prolapse [15]. The urgency of decompression surgery in CES was emphasized by Ahn et al. who noticed in his meta-analysis better prognosis if decompression was done within 48 hours, and even better prognosis was detected by Kohles et al. when surgery done earlier 
Early decompression should be preceded by prompt workup with a confirmed diagnosis by an MRI scan as soon as possible, and since this includes detecting potential patients even outside working hours and on weekends, there must be a rationale to perform MRI scans in potential cases with all the economic and logistic implications especially in peripheral hospitals where no MRI service is available after hours and over weekends. In 2019, Dionne et al. concluded that known clinical red flag symptoms are not sensitive enough to detect CES $[6,17]$.

Mechanical compression of S2, S3 and S4 nerve roots can be picked up early as they can cause weakness of the detrusor muscle in the bladder wall that controls voluntary bladder function and affects its emptying capability. This can be picked up early with a bladder scan and measuring the PVR volume [10]. PVR volume is utilized as a part of the screening pathway of management of back pain with bowel/bladder weakness to identify the need to involve the spine service $[18,19]$.

Domen et al., in 2009 , showed that a PVR volume $>500 \mathrm{ml}$ had a sensitivity of $100 \%$ and a specificity of $93 \%$. The study involved 58 patients where all were inspected for red flags including PVR more than $500 \mathrm{ml}$; using this high value as a cut-off point carries the risk of missing impending CES that might progress with time and might lead to irreversible CES with retention with no expected recovery of the urinary function [12].

Gooding et al., four years later, used the same cut-off point when they included 57 patients with suspected CES; 13 of them (23\%) were found to have CES on MRI scan. Surprisingly, they showed much less impressive conclusion with the sensitivity of PVR at $38 \%$ and the specificity $76 \%$ [5].

Hoeritzauer et al., in 2018, included 276 patients of whom only 65, a third of the patients, had recorded PVR, as the study focused on differentiating MRI scan positive and negative CES. A cut-off point of PVR $>100 \mathrm{ml}$ was used. The sensitivity and specificity were $67 \%$ and $52 \%$, respectively [13].

In 2019, Venkatesan et al., in a prospective study hypothesized $>200 \mathrm{ml}$ PVR as the most reliable cut-off point. The study included 92 patients, which is the largest number of patients involved amongst all studies. The sensitivity was $94 \%$ and specificity $72 \%$. The probability of CES was $43 \%$ ( $\mathrm{P}<0.000003)$. This is an adequate evidence for the relationship between CES and PVR, with a reasonable cut-off point for PVR [9].

More recently, from the same institute in 2020, Katzouraki et al. followed 260 patients and found a similar predictive value of $200 \mathrm{ml}$ with CE compression on MRI, and where candidates underwent subsequent surgery ( $\mathrm{P}<0.0001$, Fisher's exact test). The PVR volume $>200 \mathrm{ml}$ had a sensitivity of $94 \%$ in predicting CES and specificity $66.8 \%$, with $29.9 \%$ positive predictive value and $98.7 \%$ negative predictive value [14].

There are a number of limitations to this study. A limited numbers of articles fit with the scope of the systematic review. All studies are retrospective except for two, and there are no randomized controlled trials and meta-analysis studies.

\section{Conclusions}

Post-void urine volume using a bladder scan is essential in the diagnosis of CES. The most suitable cut-off point with statistically significant sensitivity and specificity correlation with the study samples would be PVR >200 ml. There is a need for a large-sample size prospective trial with a multi-center input to clearly delineate the true role of bladder scan as a screening tool for CES. It is unclear how accurate a bladder scan is to dictate the need for an urgent MRI scan in early cauda equina compression (incomplete CES); however, it definitely represents a valuable adjunctive tool. Furthermore, a meta-analysis might help in determining the optimal cut-off PVR to guide when we should proceed to an MRI scan.

\section{Additional Information \\ Disclosures}

Conflicts of interest: In compliance with the ICMJE uniform disclosure form, all authors declare the following: Payment/services info: All authors have declared that no financial support was received from any organization for the submitted work. Financial relationships: All authors have declared that they have no financial relationships at present or within the previous three years with any organizations that might have an interest in the submitted work. Other relationships: All authors have declared that there are no other relationships or activities that could appear to have influenced the submitted work.

\section{Acknowledgements}

We would like to thank Margaret Theaker, Librarian, Kettering General Hospital, for her kind support.

\section{References}


1. Terao T, Kato N, Ishii T, et al.: Spontaneous hemorrhage of a spinal ependymoma in the filum terminale presenting with acute cauda equina syndrome: case report. NMC Case Rep J. 2016, 3:91-95. 10.2176/nmccrj.cr.2015-0295

2. Kavanagh M, Walker J: Assessing and managing patients with cauda equina syndrome . Br J Nurs. 2013, 22:134-137. 10.12968/bjon.2013.22.3.134

3. Gardner A, Gardner E, Morley T: Cauda equina syndrome: a review of the current clinical and medico-legal position. Eur Spine J. 2011, 20:690-697. 10.1007/s00586-010-1668-3

4. Ahad A, Elsayed M, Tohid H: The accuracy of clinical symptoms in detecting cauda equina syndrome in patients undergoing acute MRI of the spine. Neuroradiol J. 2015, 28:438-442. 10.1177/1971400915598074

5. Gooding BW, Higgins MA, Calthorpe DA: Does rectal examination have any value in the clinical diagnosis of cauda equina syndrome?. Br J Neurosurg. 2013, 27:156-159. 10.3109/02688697.2012.732715

6. Germon T, Ahuja S, Casey ATH, Todd NV, Rai A: British Association of Spine Surgeons standards of care for cauda equina syndrome. Spine J. 2015, 15:S2-S4. 10.1016/j.spinee.2015.01.006

7. Ahn UM, Ahn NU, Buchowski JM, Garrett ES, Sieber AN, Kostuik JP: Cauda equina syndrome secondary to lumbar disc herniation: a meta-analysis of surgical outcomes. Spine (Phila Pa 1976). 2000, 25:1515-1522. 10.1097/00007632-200006150-00010

8. ACR guidance on COVID-19 and MR use . Accessed: January 6, 2021: https://www.acr.org/ClinicalResources/Radiology-Safety/MR-Safety/COVID-19-and-MR-Use.

9. Venkatesan M, Nasto L, Tsegaye M, Grevitt M: Bladder scans and postvoid residual volume measurement improve diagnostic accuracy of cauda equina syndrome. Spine (Phila Pa 1976). 2019, 44:1303-1308. 10.1097/BRS.0000000000003152

10. Coombes GM, Millard RJ: The accuracy of portable ultrasound scanning in the measurement of residual urine volume. J Urol. 1994, 152:2083-2085. 10.1016/s0022-5347(17)32314-5

11. Post-void bladder scanning in acute cauda equina syndrome . (2018). Accessed: January 6, 2021: https://clinicaltrials.gov/ct2/show/NCT02806167.

12. Domen PM, Hofman PA, van Santbrink H, Weber WE: Predictive value of clinical characteristics in patients with suspected cauda equina syndrome. Eur J Neurol. 2009, 16:416-419. 10.1111/j.1468-1331.2008.02510.x

13. Hoeritzauer I, Pronin S, Carson A, Statham P, Demetriades AK, Stone J: The clinical features and outcome of scan-negative and scan-positive cases in suspected cauda equina syndrome: a retrospective study of 276 patients. J Neurol. 2018, 265:2916-2926. 10.1007/s00415-018-9078-2

14. Katzouraki G, Zubairi AJ, Hershkovich O, Grevitt MP: A prospective study of the role of bladder scanning and post-void residual volume measurement in improving diagnostic accuracy of cauda equina syndrome. Bone Joint J. 2020, 102-B:677-682. 10.1302/0301-620X.102B6.BJJ-2020-0195.R1

15. Jennett WB: A study of 25 cases of compression of the cauda equina by prolapsed intervertebral discs . J Neurol Neurosurg Psychiatry. 1956, 19:109-116. 10.1136/jnnp.19.2.109

16. Kohles SS, Kohles DA, Karp AP, Erlich VM, Polissar NL: Time-dependent surgical outcomes following cauda equina syndrome diagnosis: comments on a meta-analysis. Spine (Phila Pa 1976). 2004, 29:1281-1287. 10.1097/00007632-200406010-00019

17. Dionne N, Adefolarin A, Kunzelman D, et al.: What is the diagnostic accuracy of red flags related to cauda equina syndrome (CES), when compared to magnetic resonance imaging (MRI)? A systematic review. Musculoskelet Sci Pract. 2019, 42:125-133. 10.1016/j.msksp.2019.05.004

18. Todd NV: Quantifying the clinical aspects of the cauda equina syndrome - The Cauda Scale (TCS) . Br J Neurosurg. 2018, 32:260-263. 10.1080/02688697.2018.1441975

19. Buell KG, Sivasubramaniyam S, Sykes M, Zafar K, Bingham L, Mitra A: Expediting the management of cauda equina syndrome in the emergency department through clinical pathway design. BMJ Open Qual. 2019, 8:e000597. 10.1136/bmjoq-2018-000597 